The Universality of Gricean Interpretation

Author(s): Georgia M. Green

Proceedings of the Sixteenth Annual Meeting of the Berkeley Linguistics Society (1990), pp. 411-428

Please see "How to cite" in the online sidebar for full citation information.

Please contact BLS regarding any further use of this work. BLS retains copyright for both print and screen forms of the publication. BLS may be contacted via http://linguistics.berkeley.edu/bls/.

The Annual Proceedings of the Berkeley Linguistics Society is published online via eLanguage, the Linguistic Society of America's digital publishing platform. 


\title{
The Universality of Gricean Interpretation
}

\author{
Georgia M. Green \\ University of Illinois
}

\section{Introduction}

The notion of implicature is now about 23 years old-over 33 if you trace it back to its origins in Grice's paper "Meaning", which emphasizes the importance, even for so-called literal (or "non-natural") meaning, of the speaker's intention in having her communicative intentions recognized. This is a notion that has proven critical to progress observed not only in the field of semantics, which it was originally intended to contribute to, but also in syntax, which it freed from bonds to non-semantic (i.e., non-truth-conditional) meaning, and in the study of language behavior generally (e.g., studies of rhetoric and politeness).

Nonetheless, perceptions of the domain of the principles that Grice described in "Logic and Conversation" are widely varied and quite disparate. My purpose is to show that, first of all, Grice intended a broad rather than a narrow interpretation of conversation relative to possible kinds of language use, and that, strictly speaking, the basis of implicature is the more general Cooperative Principle (CP) rather than the more specific maxims, which are neither culturally prescribed standards, nor mere customs, but more like default instantiations of the CP. I will also argue that Grice saw the relevance of the CP to language use as just the linguistic reflex of its general relevance. He saw it as governing all rational behavior. If it does, we should certainly find it universally applicable with regard to language use, and I know of no genuine counterexamples. Finally, it should figure in the interpretation of language generally, not just clever talk, and indeed, should figure in the interpretation of behavior generally, whether communicative or not. I will suggest that a case can be made that it does just that.

\section{Conversation}

It seems logical to begin with the narrowest possible interpretation of the domain Grice might have intended for his analysis of implicature. A very large number of writers who claim familiarity with the proposals of "Logic and Conversation" appear to believe that they pertain exclusively to oral communication, and in particular, oral communication that involves two or more individuals exchanging information, that is, what we call casual conversation or small talk. They appear to believe that Grice's analysis is not intended to apply to non-interactive modes of language use, e.g., to the production and interpretation of narrative, expository, persuasive or didactic discourse (including labels and instructions).

Thus, Sperber and Wilson (1986:261), for example, assert that "Grice's theory is put forward as a theory of "conversation", going on to say that it has "been taken as a more general theory of verbal communication, and Grice has done nothing to correct that interpretation." Pratt (1981) and Schauber and Spolsky (1986:116) 
assume that the CP and the maxims do not cover situations in which only one person is talking.

Other writers seem to think that the scope of the theory is limited because it does NOT include small talk. Lyons (1977:593) appears to assume that the maxims do not apply to "utterances whose function is something other than that of augmenting the addressee's store of propositional knowledge," and so criticizes them for not relating to the "semantic information contained in everyday languageutterances" which he considers "social and expressive, rather than descriptive." Along similar lines, Stubbs (1983:101) expects different rules for social discourse ("small talk", "just chatting", "phatic communication") than for what he terms transactional discourse.

Despite the presence of the word conversation in the title of Lecture II, it is evident from examining the text that Grice was not referring exclusively to social conversation or small talk. As far as I can tell, Grice uses both conversation (seven tokens, excluding the title), and talk exchange (ten tokens) to refer to the same thing: the purposeful use of natural language. ${ }^{1}$ In fact, in one place (1975:49) he equates conversation and communication, and refers to "the goals that are central to conversation/communication." Perhaps more significantly, of the 15 examples of natural language implicature that Grice gives (see Table I), only two strike me as representing small talk particularly (examples a, c about jail, and about whether Smith has a girlfriend), though several (e.g., b, h, j, k, l, and o) are pretty "gossipy", and only the three (examples b, $d$ and 1 ) that involve getting petrol, divulging someone's friend's address in the south of France, and changing the subject when someone referred to as an "old bag" enters the room necessarily involve oral as opposed to written discourse, and interactive as opposed to monologic discourse.

a. He hasn't been to prison yet.

b. There is a garage round the corner.

c. He has been paying a lot of visits to New York.

d. Somewhere in the south of France.

e. Mr. X's command of English is excellent and his attendance at tutorials has been regular.

f. Women are women. War is war.

g. $P$. It is certain that $P$. The evidence for $P$ is $Q$.

h. $\mathrm{X}$ is a fine friend.

i. You are the cream in my coffee.

j. He was a little intoxicated.

k. She is probably deceiving him this evening.

1. The weather has been quite delightful. ...

m. I sought to tell my love, love that never told can be.

n. Peccavi.

o. Miss X produced a series of sounds that corresponded closely with the score of 'Home sweet home'.

TABLE I: Examples of particularized conversational implicature from "Logic and Conversation" 
Finally, in two places, Grice takes the trouble to single out casual conversation as just a special case of talk exchange.

[The purpose or direction of a talk exchange] ... may be so indefinite as to leave very considerable latitude to the participants (as in a casual conversation). (1975:45)

In characteristic talk exchanges, there is a common aim even if, as in an over-the-wall chat, it is a second-order one, namely, that each party should, for the time being, identify himself with the transitory conversational interests of the other. (Grice 1975:48; italics mine)

Likewise, despite the ubiquitous references to "talk exchanges", there is no reason to assume that Grice meant for his analysis to be an account of oral discourse to the exclusion of written communication as some writers (e.g. Pratt 1981) assume. Indeed, three or four of Grice's own examples (examples e, m, n, o in Table I), the letter of recommendation, Blake's line, the telegram from the British General, and the singing critique involve written language, and are described without any comment on this fact.

Grice's use of written language examples also indicates that it is a mistake to assume that he did not intend his analysis to apply to non-interactive discourse (such as narrative, exposition, and persuasive speech) on the grounds that they are not literally exchanges of talk. Written language and monologues would be artifacts of irrational behavior in the extreme if they did not presuppose the existence of some intended addressee or class of addressees, or at least that there would be some such.

\section{The nature of the maxims}

The central mechanisms which drive the Gricean inference engine are the notion, from the 1957 paper, that recognition of an agent's intention is part and parcel of identifying what act the agent performs, and the $\mathrm{CP}$, the idea that rational language behavior is "such as is required, at the stage at which it occurs, by the accepted purpose or direction" of the enterprise in which the agent is engaged. Together these notions imply that speaker and hearer are constantly involved in the interpretation (usually not conscious) of what each other's goals must be in saying what they say. Grice described four categories of special cases of this principle (i.e., applications of it to particular kinds of requirements), and gave examples of their application in both linguistic and non-linguistic domains.

I speak quite deliberately in describing the "maxims" as just special cases of the CP. They are not (contra Lycan 1984:75) logical consequences (corollaries), because they don't follow as necessary consequences in all possible worlds. They are not additional stipulations. They are not necessarily an exhaustive list of special cases. Rather, they are just particular instantiations of ways of being cooperative; ALL OTHER THINGS BEING EQUAL, compliance with the CP involves conforming to all of them. When you can't conform to all of them, as Grice discusses, you do the best you can. 
It is important to understand that the maxims do not constitute the CP either, as some writers seem to think. On the contrary, the CP is a very general principle which defines, depending on the values shared by participants, any number of maxims instantiating ways of conforming to it. ${ }^{2}$ Thus, Sperber and Wilson's complaint [that Grice might need more than nine maxims] is beside the point:

Are there just the nine maxims Grice mentioned, or might others be needed, as he suggested himself? It might be tempting to add a maxim every time a regularity has to be accounted for. However this would be entirely ad hoc. (Sperber and Wilson 1986:36)

Equally important, the maxims are not rules or norms that are taught or learned, as some writers appear to believe. Thus, Pratt (1981:11) refers to "Grice's rules", and Brown and Yule (1983:32) describe the maxims as "norms speakers operate with" and Blum-Kulka and Olshtain refer to them as "norms of conversation" $(1986: 174)$ and "normative rules of speech behavior" (1986:175). Allwood et al. (1977:37) refer to Grice (1975) as providing an account of "communicative norms which aim at making the exchange of information in a speech situation as effective as possible." Similarly, Ruhl (1989:96) refers to the maxims as "normative rules of appropriateness, adequacy, and relevance." Sperber and Wilson (1986:162) characterize Grice's principle and maxims as "norms which communicators and audience must know in order to communicate adequately,"3 in contrast to their own principle, which they describe as a generalization about communication. ${ }^{4}$

Now, regardless of whether norms is understood as referring to prescriptive rules (cf. Brown and Yule 1983:32) or to customs (cf. Brown and Yule 1983:83), norms are not what Grice was referring to. It is really unfortunate that he articulated the maxims as imperatives, because there is nothing in Grice (1975) to suggest that he thought of them as statistical principles that people tend to conform to, or as ideals that people aspire to conform to. Rather, they are described as governing the communicative acts of all (sane) communicators.

That the maxims are just obvious ways of BEING cooperative, and not rules we have to learn, suggests that they may only come to our attention when we encounter speech which is hard to reconcile with the assumption that they are being observed, and this seems to be the case. Sperber and Wilson's Principle of Relevance can be seen as not being effectively distinct from the claim, consistent with the CP, that the maxim of relevance is always assumed to be observed.

Perhaps I can illustrate the tenacity with which we assume that speakers observe the $\mathrm{CP}$, and in particular the maxim of relevance, by examining what we might make of an apparently irrelevant speech act. Suppose a stranger were to approach me in a public place, and after introducing himself, ask the time. I would surely think this very strange, and wonder why he introduced himself.

1. Excuse me, I'm Sterling Ryznich. Can you tell me the time? 
Why did he think I would care who he was if all he wanted was the time? It is only when we come across an utterance whose relevance is not easily inferred that we notice that we expect every utterance in a discourse to be relevant to some participant's goal which is at least mutually accessible, if not truly shared. If the hearer assumes that the speaker is abiding by the $\mathrm{CP},{ }^{5}$ he must adopt a strategy of interpreting the speaker's behavior as conforming to the maxims, and considering what propositions must be assumed in order to make that behavior patently in conformity with the $\mathrm{CP}$ and the maxims.

Since the speaker (as a speaker-hearer of a natural language spoken in a society) expects the hearer to adopt this strategy for interpreting speech behavior, the speaker is free to exploit this fact, and speak in such a way that his behavior must be interpreted according to it. If the speaker's remark seems irrelevant, the hearer will seek to construct a sequence of inferences which make it relevant to some assumed goal.

In the case of (1), we have two choices: either assume that the introduction is truly irrelevant to any purpose of speaker or hearer, in which case we should consider the stranger truly deranged, or assume that there is some goal to which the stranger's identity is relevant. Maybe it is a goal of his: maybe he wants to use me as an alibi (I'd certainly remember bizarre behavior like uttering (1)). Maybe he is trying to terrorize me psychologically, and just wants me to worry about why he said what he said. On the other hand, maybe it is relevant to some goal he imputes to me. Maybe he (mistakenly) thinks I am someone who was supposed to meet him. Maybe he thinks he is such a celebrity that even though he never expects to see me again, I would want to know whom I had befriended. Maybe he just wants to know the time, but believes that the injunction against speaking to strangers will inhibit me from answering him unless he introduces himself, making him no longer a stranger. And so on. Only our imagination limits the goals, and beliefs about my goals, that we might attribute to the speaker. The point is that if we reject the assumption that the speaker is irrational, then we must at the very least assume that there is some goal to which his introduction is relevant in the context of asking the time, even if we can't imagine what it is.

\section{Purposes and rationality}

One further point seems to require discussion here. What Grice intended to refer to by purpose and goal in "Logic and Conversation" is apparently even less clear than the intended referent of conversation and talk exchange. Others' strategy has apparently been to take a fairly literal approach to both questions, investing Grice's numerous hedges and apologies (e.g., pp. 47, 49) with a great deal of significance, and arriving, logically, at very narrow interpretations. Thus, Sperber and Wilson (and Pratt and many others) seem to think that the purposes of participants in talk exchanges which Grice refers to must be mutual, cooperative purposes, and of a knowledge-oriented nature, like understanding the economy of Rumania, or figuring out how to put together a pump. 
Grice assumes that communication must have 'a common purpose or set of purposes, or at least a mutually accepted direction' (Grice 1975:45) over and above the aim of achieving successful communication. We do not mean to deny that this is very often true, particularly in conversation. In a talk exchange, a seminar or a book, there may well be a mutually manifest purpose or direction. (Sperber and Wilson 1986:161-162)

Now, I have read "Logic and Conversation" a number of times over the last 23 years. Since I have been unable to arrive at a coherent, consistent literal interpretation, my strategy has been to assume that Grice's ability to say clearly what he meant just did not match his vision, ${ }^{6}$ and therefore, to interpret problematic terms in such a way as to arrive at a consistent and explanatory theory. To me, this beats accepting either of the alternative conclusions: that Grice's goal (and thus the scope of his analysis) must be very narrow, or that he was short-sighted (to put it politely), and simply did not think through the consequences of the propositions constituting his analysis. I do not claim credit for the interpretation I support here, since I think it is at least implicit in what he wrote, and since I am sure I have been influenced in its favor by others, ${ }^{7}$ but if it should turn out to be not what Grice meant at all, I should still prefer it.

Grice indicates at several points that he sees discourse as purposive behavior. That is, he presumes that participants have goals in participating (apparently since otherwise they wouldn't be participating). This is the gist of the first passage referring to purposes:

each participant recognizes in [talk exchanges], to some extent, a common purpose or set of purposes, or at least a mutually accepted direction.

(Grice 1975:45)

Grice is very vague about these purposes: how many there are, how shared they have to be. With twenty years of hindsight, and close attention to this question, we can say that the purposes are first of all not unique. Conversants typically have hierarchically embedded goals. Taking the most transparent sort of case, Martha may say " $X$ " to George, with the immediate goal that George understand that Martha has said " $\mathrm{X}$ ", and meant some transparently derivable proposition $p$ by it, so that George will believe that Martha believes that $p$ is true, so that George, respecting Martha's opinion, will come to believe $p$ himself. Presumably Martha has a reason for wanting George to believe $p$ (another goal), and probably reasons (and goals) behind that. If we were to assume that only one of these was "Martha's goal", I don't know what grounds we could use to decide which one it was, that is, which was the unique correct level of analysis.

Second, goals are not so much shared or mutual, as they are mutually modelled (Cohen and Perrault 1979, Cohen and Levesque 1980, Green 1982, Appelt 1985, Cohen and Levesque 1990, Perrault 1990): for George to understand Martha's utterance of "X" to George, George must have beliefs about Martha which include Martha's purpose in uttering " $X$ " to George, which in turn includes Martha's model of George, including George's model of Martha, etc. ${ }^{8}$ Grice's comment (1975:48) that 
"in characteristic talk-exchanges, there is a common aim even if...it is a secondorder one, namely, that each party should, for the time being, identify himself with the transitory conversational interests of the other" can be interpreted along these lines. The idea that participants will at least temporarily identify with each other's interests, i.e., infer what each other is trying to do, is what allows quarrels, monologues, etc. (pace Pratt and Schauber and Spolsky ${ }^{9}$ ) to be included in the talk exchanges that the CP governs. The participants may have different values and agendas, but given Grice's (1957) characterization of conventional meaning, for any communication to occur, for each partici-pant to understand what the other meant, each must make assumptions about the other's goals, at least the low-level communicative goals. This is the sense in which participants recognize a "common goal". When the assumptions participants make about each other's goals are incorrect, and this affects non-trivial beliefs about each other, we say they are "talking at crosspurposes", precisely because of the mismatch between actual goals and attributed goals.

Finally, and I think Grice's recognition of this is clear from the continuation of the passage on p. 45, and from remarks three pages later, each individual in a talk exchange may be directing her behavior towards a multitude of goals (or purposes), and these may be independent of each other, or hierarchically linked.

This purpose or direction may be fixed from the start (e.g., by an initial proposal of a question for discussion), or it may evolve during the exchange; it may be fairly definite, or it may be so indefinite as to leave very considerable latitude to the participants (as in a casual conversation). (1975:45)

The participants have some common immediate aim, like getting a car mended; their ultimate aims may, of course, be independent and even in conflict- (1975:48)

Thus, $\mathrm{S}$ may have as a goal to get $\mathrm{H}$ not to vote for Sen. Foghorn, but she may also intend to maintain good social relations with $\mathrm{H}$, and therefore intend to flatter $\mathrm{H}$ (or boost his positive face) in order to get $\mathrm{H}$ to believe that not voting for Foghorn was his own idea.

Grice's references to discourse as purposive behavior, are regularly linked with references to the rationality of human beings, and it is this fact, along with the analogues in three separate places on pp. 47 and 48 to non-linguistic behavior, that invites us to understand the $\mathrm{CP}$ as something that governs not just discourse, but rational intentional behavior generally. ${ }^{10}$

Our talk exchanges do not normally consist of a succession of disconnected remarks, and would not be rational if they did. They are characteristically, to some degree at least, cooperative efforts; and each participant recognizes in them, to some extent, a common purpose or set of purposes... at each stage, SOME possible conversational moves are excluded as conversationally unsuitable. (1975:45) 
one of my avowed aims is to see talking as a special case or variety of purposive, indeed rational, behavior (1975:47)

one feels that the talker who is irrelevant or obscure has primarily let down not his audience but himself. (1975:48-49)

Insofar as the first and last passages are equally true of agents and interactants generally, not just talkers, they support the interpretation of the CP and the attendant maxims as descriptive of and relevant for interactive behavior generally, not just discourse.

The discussion of example (1) indicated that interpreting the communicative behavior of other human beings as intentional, and relevant, necessary, and sufficient for the achievement of a presumed goal seems to be unavoidable-maybe we are born to do it. This is equally true of behavior that isn't intended as communicative. For example, Morgan (1978) described a situation where someone is standing at a door, gripping a key that is inserted in a lock, and making partial rotary motions with his wrist and forearm. It is very difficult to describe this without prejudicing the interpretation, but that only strengthens my point: no matter how I describe it, if we imagine it, we impute some purpose to the person, and it involves the key and the lock-probably using the key to lock or unlock the door, but it could be something less usual, like an isometric exercise. My point is that we do not seem to entertain the idea that he might be doing it for no reason. That alternative, along with the possibility that he isn't even doing it, that it's just happening to him, is one that I think we are very reluctant to accept without any independent support, such as knowledge that people do that sort of thing as a nervous habit, like drumming their fingers on a hard surface, or playing with their hair.

The understanding of social meanings in casual conversation may work similarly. When Martha asks how George is, or states the obvious to make social conversation, it isn't so much the propositional content of what Martha says that informs George and contributes to a mutually accessible goal. Rather, it is the fact that Martha has gone to the trouble to ask the question, or evoke the happy or commiserable thought, that is interpreted as intentional behavior. Interpreting it as intentional, George unavoidably tries to infer why it was intended (e.g., to cause him to believe that Martha cares enough to go to the trouble to make small talk). As with other sorts of meaning, such inferences about intentions are intended to be made. Thus, the sharing of "social and expressive" information in small talk seems to be governed by the same general principles of interpretation that govern the interpretation of other intentional and communicative acts.

I hope I have made it clear that "cooperative" in the sense of the Cooperative Principle does not entail accepting your interlocutor's goals as your own and helping her to achieve them. Rather, it is most usefully understood as meaning no more-and no less-than 'willing to try to understand the interaction from the other participants' point of view', i.e., to try to understand what their goals and assumptions must be. 


\section{The geographical generality of Grice's principles}

In talking about the observance of the $\mathrm{CP}$ as rational, Grice (1975: 47, 49) implies that he takes it and the maxims to represent values universally assumed in human society. Grice does not explicitly claim universality for the CP and the maxims, but if they are to explain discourse phenomena as a function of rationality, they have to be universal (barring societies of irrational beings), and hence potentially a consequence of some property of human nature or human society, and not just of familiar English-speaking cultures. Consequently, insofar as the maxims are only instantiations in a context of the $\mathrm{CP}$, and not corollaries, discovering that one of the maxims was not universal would not invalidate claims that the Cooperative Principle was universal.

However, attempts to show that one or other of the maxims is not valid in some society usually end up showing something a little different, namely that conforming to the maxims is constrained by cultural values, such as deferring to superiors, being indirect or noncommittal (to protect one's "face" (or cover one's ass)), belonging to an information elite, protecting the "negative face" of others (e.g., by refraining from making personal references or otherwise imposing, and from assigning blame, etc.). Thus, being cooperative in making one's contribution "such as is required at the stage at which it occurs" to accomplish one's goal(s) may involve following other principles as well, such as:
A. Assigning responsibility for a state of affairs that could be construed as undesirable is counterproductive.
B. Making the addressee disinclined to cooperate (e.g., by making the addressee uncomfortable) is counterproductive.
C. Maintaining social advantage is useful.

What counts as an undesirable state of affairs, as making someone uncomfortable, and as constituting social advantage, are of course defined relative to a particular culture.

Thus, cultures can be expected to differ in the values they assign to various ways of being cooperative, and matters of avoiding offense and losing face can be expected to interact with these, since the behaviors that count as offensive and as contributing to status are well-known to be defined differently in different cultures. But it would astonish me to find a culture in which Grice's maxims were not routinely observed, and required for the interpretation of communicative intentions, and all other things being equal, routinely exploited to create implicature.

\section{The behavioral generality of the principles}

If the $\mathrm{CP}$ and the maxims are understood as principles of rational behavior-or as principles defining rational behavior, one would expect to find them involved in interactions of all sorts, not just "clever" uses of language, like the gossipy or catty uses Grice cites (e.g., examples a, d, e, l, n, o in Table I). To begin with, the case 
has been made (by both Nunberg (1978) and Sperber and Wilson (1986)) that the literal interpretation of linguistic expressions in general involves the same mechanisms as conversational implicature, though Grice came close to recognizing this in his discussion of generalized conversational implicature as involved in examples like (2) (cf. Horn (1984)).

2a. $\mathrm{X}$ is meeting a woman this evening.

$2 \mathrm{~b}$. $\mathrm{X}$ broke a finger yesterday.

Nunberg (1978) argued (cf. also discussion in Green (1989)) that the maxims and the $\mathrm{CP}$ are involved in a process paralleling conversational implicature in determining the reference in context of uses of ordinary nouns and verbs such as newspaper or run, and proper names, as in (3-5).

3. Rupert bought another newspaper.

4a. Ronnie is running.

4b. The engine is running.

4c. The program is running.

4d. The electricity is running.

5a. The population of Chicago is over 5 million.

5b. Chicago beat Dallas 44-0.

Nunberg argues that such terms are not in general lexically ambiguous, but vague, and their interpretation in context is a matter of inferring first, what class of referents the speaker takes to be normal for that term in that speech situation (i.e., making assumptions about the hearer's beliefs about the world), and second, what derivative function relates the referent she intends to that class. Understanding the contextually indicated reference of metaphors and other extensions of "literal" meaning, for example, a spark of anger, to sail a report across a desk, follows as a particular subcase, under Nunberg's analysis (Nunberg 1988).

Whether or not Grice realized the variety of examples that could be explained by analyses along the lines he suggested for and and or is not really important, and whether one should characterize interpretation of non-obvious purposive behavior generally as implicature seems to me an arid question of nomenclature, not a question of analysis.

In any case, a further consequence of the $\mathrm{CP}$, and of the maxim "Be relevant" in particular, that Grice never discussed, is that it provides the basis for a natural account of the problem of the coherence of texts, that is, of elucidating what it is that makes (6) a plausible discourse, in contrast to (7), which appears to be just a string of sentences related only by temporal or spatial order. 
6. The following days were unlike any that had gone before. There wasn't a man on the ranch who didn't know of Saturday's race and the conditions under which it would be run. They gave any excuses to get near the black stallion's corral. [Walter Farley, The Black Stallion, p. 199. New York: Random House (1953)]

7. The sun climbed higher, and with its ascent the desert changed. There was nothing Lucy liked so much as the smell and feel of fur. One evening, after dark, she crept away and tried to open the first gate, but swing and tug as she might she could not budge the pin. ${ }^{11}$

If we assume that the underlying organizational principle for discourse is simply the assumption that the sequence of sentences at issue is produced by an individual in order to achieve some goal in accordance with the CP, then it follows, given no indication to the contrary, that each sentence is uttered in the execution of some plan to achieve that goal and conforms to the maxims that instantiate the CP, and is thus intended to say something necessary, true, and relevant to accomplishing that goal. Then, a coherent text is one where the interpreter can readily reconstruct the speaker's plan with reasonable certainty, by inferring relations among the sentences, and their individual relations to the various subgoals in the inferred plan for the enterprise or enterprises understood to be at hand.

Coherence, in this approach, depends not on properties of the text components themselves, either individually or in relation to each other, but rather, on how great an effort is required to construct a reasonable plan to attribute to the text-producer in producing the text. This in turn depends on how hard or easy it is to take each sentence as representing a true, necessary, and relevant contribution to that plan.

Some writers (cf. Lakoff 1973, Leech 1983, Brown and Levinson 1987) have interpreted the $\mathrm{CP}$ and the attendant maxims as constituting a theory of informative behavior, which they see as generally contrasting and/or conflicting with principles governing politeness, apparently assuming that the goals of being polite and being informative tend to conflict. Grice himself implies that "Be polite" ranks as a maxim of the CP along with Quantity, Relevance, etc.:

There are, of course, all sorts of other maxims (aesthetic, social, or moral in character), such as 'Be polite', that are also normally observed by participants in talk exchanges, and these may also generate nonconventional implicatures. (1975:47)

The CP would seem to entail politeness whenever the addressee's positive feelings toward the speaker are essential to the speaker's accomplishing her goals. Brown and Levinson (1987) recognize a number of ways in which what they call Grice's "conversational maxims" (Quantity, Quality, Relevance and Manner) are exploited in the service of politeness strategies.

I want to suggest that more generally, a large measure of what makes any linguistic act polite must be attributed to the assumption that participants are acting in accordance with the $\mathrm{CP}$ and the various maxims. I follow Brown and Levinson's practice in using politeness to refer to whatever means are employed to display con- 
sideration for one's addressee's feelings (or face), regardless of the social distance between the speaker and addressee. Insofar as being polite, on this interpretation, involves a wide variety of strategies depending on estimates of the social distance between speaker and addressee, the relative social status of speaker and addressee, and the extent to which the act contemplated is considered to be an imposition in the culture which speaker and addressee are members of, when I refer to "a politeness maxim", I will have in mind something like maxim B above.

Politeness, according to Brown and Levinson $(1978,1987)$ is trade in a commodity they call face. FACE is defined as consisting of two components, first, the freedom to act unimpeded (negative face) and second, the satisfaction of having one's values approved of (positive face) (Brown and Levinson 1978:67). To engage in normal interaction is to risk losing face, since being asked to do something implies disapproval of your not having done it already, and puts pressure on you to act a certain way. Similarly, telling someone something implies that they did not know it already, and drawing attention to that ignorance threatens the face of the addressee, since it may amount to implicit criticism of their values and choices. Just talking to someone constitutes something of an imposition on their time.

Since face is defined in terms of approval by others, and absence of interference from others, maintaining face requires the cooperation of others, at least insofar as it requires that they show approval and refrain from acts that would constrain one's own activity. Since threatening the face of the addressee is likely to make him less willing to cooperate with the speaker in maintaining her face, and in any other goals he imputes to her, one would expect all enterprises which require cooperative interactions to involve the assumption that interactants are guided by the CP. Thus, interactants trade in face, paying face whenever in the course of accomplishing their goals, they must perform a face-threatening act such as conveying information that may be interpreted as implying a criticism, or making a request for goods or services, or even for the time that it takes to share information.

The supposed conflict between the "conversational" maxims and a politeness maxim is assumed to be obvious insofar as it is assumed to be common knowledge that it is impolite to be direct about certain things: making critical remarks, asking personal questions, bossing people about. But observed conflicts are between two kinds of goals: those that have to do directly with sharing information and inducing action, and those that have to do with preserving or enhancing the social status quo, by preserving or enhancing one's own "face" or that of one's addressee. Conflict between these goals is not a necessary consequence of anything; learning something from someone does not ENTAIL feeling threatened by that knowledge. Listening to someone is not a waste of time if you profit by it. Indeed, attaining goals that involve sharing information or inducing action regularly depends on success in keeping the addressee happy and cooperative by maintaining his face. Consequently, making one's contribution such as is required at the stage at which it occurs will involve whatever is necessary to secure the cooperation of the addressee (cf. Maxim B). Frequently this will involve satisfying face wants, and avoiding threats to the face of the addressee. Thus, Maxim B, and such submaxims as "Don't impose", "Offer options", and "Make the addressee feel good", ${ }^{12}$ follow from the CP in the same 
way that "Be brief" and "Be orderly" do. They are additional ways of making your contribution "such as is required, at the stage at which it occurs, by the accepted purpose or direction of the talk exchange in which you are engaged" (Grice 1975:45). At the same time, politeness displays convey information about the speaker's beliefs and wants concerning the relationship between speaker and addressee, and consequently, implicature is a key component in a number of politeness strategies, not just the move-relatively drastic in Brown and Levinson's hierarchy (Brown and Levinson 1978:65)-of going off-record by implicating rather than speaking in a more direct fashion. The relation between being polite and being informative is one of symbiosis regulated by the $\mathrm{CP}$, not one of antagonism between the $\mathrm{CP}$ and a politeness maxim on the order of "Encourage cooperativeness".

We can examine a couple of cases as illustration. A common positive politeness strategy (making the addressee feel good) involves the use of special deferential forms, such as formal second person pronouns in German and Spanish, and deferential affixes on nouns and verbs, as in Japanese and Korean. By convention, the use of deferential forms indicates the speaker's respect for the addressee, referent, or bystander; it is customary to use them when addressing a person to whom one is expected to show deference, for example, teachers, parents, grandparents. Consequently, they are typically employed 1) to mitigate face threat by feeding the addressee's ego, by explicitly acknowledging her superior status, or 2) to minimize face threat by implying that since the addressee is so superior in status and authority to the speaker, the speaker is not in a position to demand or force any action or reaction from the addressee. Here, it is particularly implicatures from the formal, possibly comparatively obscure manner of speech that create the intended positive politeness effect. As one might expect, speakers of Korean and Japanese further exploit this rich system in sarcasm and in switching levels of honorification to implicate that the relationship between the speaker and the addressee has changed, or that it should change to the relation implied by the honorific morphemes. Similarly, in English- speaking cultures, strangers who want to have the privileges of an intimate relationship (e.g. insurance salesmen and telephone solicitors) often use positive politeness tactics to imply that that relation already exists, asking personal questions about the addressee's family and state of mind (Good evening. How are you tonight? And how is Mr. Green?). Often telephone solicitors don't identify themselves at the beginning of the interaction, and address you by your first name, speaking as if you should know who they are and reciprocate with intimate, positive politeness behavior.

Avoiding imposing by employing hedges and euphemism and conventional indirect speech also amounts to performing a linguistic act in a particular way. Thus it also involves an implicature, according to the maxim of manner, from the fact that the speaker took the trouble to go through the motions of attempting to protect the addressee's face. Furthermore, as Lakoff (1973:305) pointed out, insofar as "Don't impose" entails "Don't waste time", being polite according to this strategy entails being considerate by conforming to all of the so-called informativeness maxims.

Finally, a third strategy consists of going off-record and implicating even more obliquely the opinions and wants that the speaker would like to convey without the 
threat to the addressee's face that direct expression might imply. Going off-record involves just hinting at what you want or think, for example, saying I wish I didn't have to walk home instead of asking for a ride, or saying That style is also available in a size 14 instead of saying You'll split the seams of that size 12 if you try to put it on. Both the politeness aspect of hints and the communicative aspect work the same way as such politeness formulae as hedges: the content intended to be communicated must be inferred via the assumption that what was said is relevant to salient concerns; its politeness value is a function of the recognition of the fact that direct expression was intentionally avoided.

My point has been that the basic principles of Gricean inference are universal, and far from being specific to particular kinds of language use, are not even specific to language, but rather are part of the human condition; people of all cultures cannot help interpreting each other's actions in terms of a background assumption that the actions are rational according to the CP and whatever "maxims" follow from it IN THAT CONTEXT. I have tried to show that this does not preclude cultural differences on a grand scale. I claim that such differences are not random or arbitrary, but follow in a principled way from cultural differences in values. Because of the nature of the basic principles, it follows that they develop (as opposed to being learned) in all individuals who understand the rest of their species to be goal-directed planning organisms that act autonomously. Values, of course, have to be learned. Sometimes they have to be taught. And there is apparently a lot of individual variation in how well they are learned. Individuals also differ in their ability to correctly classify situations. And only a few may excel in developing a repertoire of techniques for balancing conflicts among goals and values-this is a fine art.

I would like to conclude by suggesting that one of the major values of implicature and exploitation of the CP in general ${ }^{13}$ is that it allows us to mean what we say at a number of different levels, and that as speakers and hearers, it is a source of enjoyment to do so. The typical implicature (I exclude sarcasm as a very special case) involves a more or less literal meaning of what is said. When you say It's cold in here to get someone to do something about it, you do mean that it's cold where you are. You wouldn't say it if you thought it was false. The typical implicature also involves a chain of inferences leading to the intended understanding; in this case: 'I'd like you to do something to make it warmer'. And typically, the fact that there is a difference between what was said literally and what was intended to be conveyed is also significant, and intended to be understood: 'I have spoken in this oblique fashion out of consideration for your feelings'-an inference involving the manner maxim.

Verbal art is the most obvious example-puns and higher rhetorical figures such as metaphor. The sign that says "Centipede Crossing-100 feet" is funny/satisfying/irritating because it is literally true on two interpretations. It is deliberately ambiguous, and you're supposed to recognize that it is and that you are supposed to recognize that.

Political art, both in the sense of persuasive rhetoric and in the sense of diplomacy, including being diplomatic generally, involves saying things in such a way 
that they will be interpreted in different-favorable-ways by different groups in the same audience (Myers 1984). Yassir Arafat's ambiguous denunciation of terrorism in 1988 is a good example of this, except that it didn't fool anybody ${ }^{14}$ Apparently, the art of diplomacy involves the art of minimizing the depth to which hearers will search for the intentions behind intentions.

My final example involves graphic art, in the sense of communicative effects of the way something is represented in visual rather than verbal terms. In one of the euphoric demonstrations following the opening of the borders between East and West Germany, the following sign was displayed.

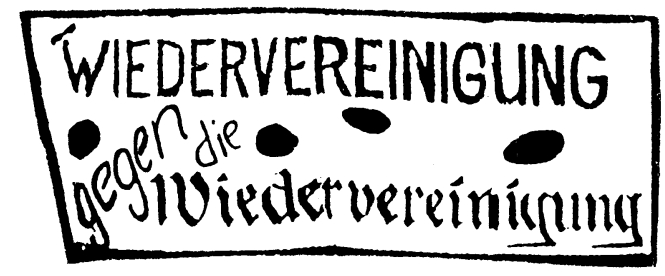

Nothing I can do with my vocal apparatus or my typewriter can reproduce the essence of this sign. To understand its message, you have to notice the difference between the token of 'reunification' (Wiedervereinigung) that is in green and red roman capitals and the token in brown Fraktur. The sign-bearers are opposed to (gegen) old-style, Third Reichian, brownshirt reunification. They favor a modernstyle reunification, involving the environmentalist Greens and the communists (the "Reds")-or on another reading, the Social Democrats, whose color is red. You have to recognize the different typestyles and colors, and realize that you are intended to recognize them, and attribute significance to them, inferring reasons why each is the way it is, and not some other way, and assume that you are intended to infer just those reasons, and intended to recognize that you are so intended, etc. Precisely the logic of "Logic and Conversation", and of Grice (1957) as well.

The spirit of Grice's theory is that behavior, communicative and otherwise, is goal-directed and is correctly interpreted only by acknowledging that it is intended to be so interpreted. The fact that Grice did not clearly articulate its breadth does not diminish its explanatory power.

\section{FOOTNOTES}

${ }^{1}$ Three other expressions, natural language and natural speech or natural counterparts occur in the introductory pages. They all seem to refer to language as a system, as opposed to utterances in a language, which is what I take talk exchange and conversation to refer to.

${ }^{2}$ Stubbs (1983:95) may recognize this in referring to the maxims as "maxims of co-operativeness", but he does not discuss how the individual maxims he invokes might be related to the more general principle. 
${ }^{3}$ In general, it seems to me, Sperber and Wilson's criticisms (see especially p. 37) are based on the false assumptions that communication is always perfect and that its perfection is what must be explained. Although they reject the code model of communication embodied by the conduit metaphor exposed by Reddy (1979), they do not consider his toolmakers' metaphor, which treats fully successful communication as comparatively rare, and generally the result of hard work by both speaker and addressee. They retain the conduit metaphor premise that if communication is unsuccessful, blame lies squarely at the feet (mouth?) of the speaker, in saying (1986:251) that "the first interpretation consistent with the Principle of Relevance will be selected, and the speaker who wants to be correctly understood must make sure that the interpretation she wants to convey is the first one consistent with the Principle of Relevance." Sperber and Wilson do not explain how this might be done with as little effort as seems to be generally expended in informal language use.

${ }^{4}$ Grice suggests (1975:49) "that anyone who cares about the goals that are central to conversation/communication (e.g., giving and receiving information, influencing and being influenced by others) must be expected to have an interest, given suitable circumstances, in participation in talk exchanges that will be profitable only on the assumption that they are conducted in general accordance with the maxims." This seems to me as much a generalization as Sperber and Wilson's Principle of Relevance: "Every act of ostensive communication communicates the presumption of its own optimal relevance" (1986:158).

${ }^{5}$ And all the maxims, unless this absolutely cannot be reconciled with the speaker's behavior.

${ }^{6}$ There is some circumstantial evidence supporting this. First, there are the ubiquitous hedges and the apologies (pp. 47,49) pounced upon by those who would circumscribe the scope or significance of Grice's programme. Second, there is the fact that Grice (apparently) was himself unsatisfied with the account, and had to be cajoled into letting lectures II and III be published 8-10 years after they were written.

${ }^{7} \mathrm{My}$ understanding (or interpretation) has benefited in ways I am sure I cannot trace, from discussion with Jerry Morgan, and from his work and that of Robin Lakoff, Larry Horn, and Penelope Brown and Steve Levinson. No ideas represented here that they would wish to disclaim should be attributed to them.

${ }^{8}$ For a non-technical discussion of this recursion, see Green 1989:13-15, et passim.

${ }^{9}$ Careful reading of "Logic and Conversation" shows that Grice cited quarrels and letter writing as instances that did not fit an interpretation of the CP that he rejected (Grice 1975:48), not one that he supported.

${ }^{10}$ For a discussion of the relevance of the $\mathrm{CP}$ and the maxims to feline behavior, see Davison (1990).

${ }^{11}$ These sentences are from Walter Farley's The Black Stallion Revolts (New York: Random House, 1953), C.S. Lewis's The Lion, the Witch, and the Wardrobe (New York: Macmillan, 1950), and Mary Norton's The Borrowers (New York: Harcourt, Brace and World, 1952) respectively. They were chosen to match the excerpt in (6) for syntax, anaphora, and introduction of noun phrases with definite articles.

${ }^{12} \mathrm{Cf}$. Lakoff (1973) and Brown and Levinson (1987:2). 
${ }^{13} \mathrm{Cf}$. Green (1988) for an extended discussion of this.

${ }^{14}$ Addressing the UN in Geneva on 13 December 1988, he said, "I condemn terrorism in all its forms, and at the same time salute those sitting before me in this hall who, in the days when they fought to free their countries from the yoke of colonialism, were accused of terrorism by their oppressors."

\section{REFERENCES}

Allwood, J., Anderson, L. G. and Dahl, Ö. 1977. Logic in language. Cambridge, England: Cambridge University Press.

Appelt, D. 1985. Planning English sentences. Cambridge, England: Cambridge University Press.

Blum-Kulka, S. and Olshtain, E. 1986. Too many words: Length of utterance and pragmatic failure. Studies in Second Language Acquisition, 8:165-180.

Brown, P. and Levinson, S. 1978. Universals in language usage: Politeness phenomena. Questions and politeness: Strategies in social interaction, ed. by E. Goody, 56-311. Cambridge, England: Cambridge University Press.

Brown, P., and Levinson, S. 1987. Politeness. Cambridge, England: Cambridge University Press.

Brown, G. and Yule, G. 1983. Discourse analysis. Cambridge, England: Cambridge University Press.

Cohen, P. and Levesque, H. 1980. Speech acts and the recognition of shared plans. Proceedings, Canadian Society for Computational Studies of Intelligence.

Cohen, P. and Levesque, M. 1990. Rational interaction as the basis for communication. Intentions in communication, ed. by P. Cohen, J. Morgan, and M. Pollack, 221-256. Cambridge, Mass: MIT Press.

Cohen, P. and Perrault, C.R. 1979. Elements of a plan based theory of speech acts. Cognitive Science, 3:177-212.

Davison, A. 1990. Do cats have propositional attitudes. Manuscript in progress.

Green, G. M. 1982. Linguistics and the pragmatics of language use. Poetics 11:45-76.

Green, G. M. 1988. Some remarks on why there is implicature. Studies in the Linguistic Sciences, 17:2:21-42.

Green, G. M. 1989. Pragmatics and natural language understanding. Hillsdale, N.J.: Lawrence Erlbaum Associates.

Grice, H. P. 1957. Meaning. Philosophical Review, 66:377-388.

Grice, H. P. 1975. Logic and conversation. Syntax and semantics, vol. 3: Speech acts, ed. by P. Cole and J. Morgan, 41-58. New York: Academic Press.

Horn, L. 1984. Toward a new taxonomy for pragmatic inference: Q-based and Rbased implicature. Georgetown University Roundtable on Languages and Linguistics, ed. by D. Schiffrin, 11-42. Washington, D.C.: Georgetown University Press.

Lakoff, R. 1973. The logic of politeness: Or minding your P's and Q's. Papers from the Ninth Regional Meeting of the Chicago Linguistic Society, ed. by C. Corum, T. C. Smith-Stark, and A. Weiser, 292-305. Chicago: Chicago Linguistic Society. 
Leech, G. 1983. Principles of pragmatics. London, England: Longman.

Lycan, W. G. 1984. Logical form in natural language. Cambridge, Mass.:MIT Press. Lyons, J. 1977. Semantics. Cambridge, England: Cambridge University Press.

Morgan, J. L. 1978. Two types of convention in indirect spr sch acts. Syntax and semantics, vol. 9: Pragmatics, ed. by P. Cole, 261-280. New York: Academic Press.

Myers, F. 1984. The language of political elites. Paper presented at the LSA/AAAL winter meeting, Linguistic Society of America/American Association of Applied Linguistics. December, 1984.

Nunberg, G. 1978. The pragmatics of reference. Bloomington, Ind.: Indiana University Linguistics Club.

Nunberg, G. 1988. Poetic and prosaic metaphor. Theoretical issues in natural language processing, 3, New Mexico SU, ed. by Association for Computational Linguistics, 177-180. New York: Association for Computing Machinery.

Perrault, R. C. 1990. An application of default logic to speech act theory. Intentions in communication, ed. by P. Cohen, J. Morgan, and M. Pollack, 161-186. Cambridge, Mass: MIT Press.

Pratt, M. L. 1981. The ideology of speech-act theory. Centrum (N.S.) 1:1:5-18.

Reddy, M. 1979. The conduit metaphor-a case of frame conflict in our language about language. Metaphor and thought, ed. by A. Ortony, 284-324. Cambridge, England: Cambridge University Press.

Ruhl, C. 1989. On monosemy. Albany: SUNY Press.

Schauber, E. and Spolsky, E. 1986. The bounds of interpretation. Stanford: Stanford University Press.

Sperber, D. and Wilson, D. 1986. Relevance: Communication and cognition. Cambridge, Mass.: Harvard University Press.

Stubbs, M. 1983. Discourse analysis. Chicago: Chicago University Press. 